\title{
Static Strength of Tubular T-joint with Reinforced Chord Under In-plane Bending Load
}

\author{
Song Shengzhi and Shao Yongbo*
}

School of Civil Engineering, Yantai University, China, 264005

\begin{abstract}
Recent research on the static strength of axially loaded tubular T-joints with chord reinforcement shows that appropriately proportioned reinforced length and thickness can significantly improve the static strength. This paper extends the numerical study to chord reinforced tubular T-joint subjected to in-plane bending load. Firstly, various aspects of the FEA strategy such as material properties, element type, mesh density, and load condition are addressed. Afterwards, $4 \mathrm{~T}$-joint models are analyzed to prove that increasing the thickness of the chord is effective to increase the static strength. Finally, the parametric investigation, which involves the length and the thickness of the reinforced chord segment, is conducted. From the parametric study, the most effective values of the length and the thickness of the reinforced chord are suggested.
\end{abstract}

Keywords: Tubular T-joint, Static strength, In-plane Bending, Finite element analysis, Failure mode, Parameter analysis.

\section{INTRODUCTION}

Steel circular hollow sections are used extensively in offshore structures due to their excellent structural and mechanical properties such as high strength versus weight ratio, high buoyancy, low drag coefficient, small corrosion surface area and so on. In these structures, the hollow section members are jointed together by welding the profiled ends of the braces onto the circumference of the chord. As high stress concentration exists near the weld toe, failure generally occurs near the weld on the hollow section surface. In recent years, a lot of research work on improving the static strength of axially loaded tubular T-joints by using reinforcing methods has been done [1-4]. Most work is focused on the analysis of tubular joints under axial load, and the research on tubular joints under in-plane bending load is relatively few, especially on reinforced tubular joints. In the literature, Y.S. Choo had studied the bearing capacity of doubler plate [5] and collar plate [10] reinforced X-joints under in-plane bending load, and established the parametric equations for assessing the static strength. As in-plane bending load is also a common loading type for tubular joints subjected to in practical tubular structures, it is also meaningful to study the static behavior of tubular T-joints under in-plane bending.

Reinforcing the critical region is used to improve the static strength for tubular T-joint. Generally, reinforcing method can be classified into internal reinforcement and external reinforcement. The aim of this study is to increase the radial stiffness of chord, and so as to improve the bearing capacity of tubular T-joints. The internal reinforcement of chord is divided into internal ring reinforcement, internal plate reinforcement, increasing the thickness of chord

*Address correspondence to this author at the School of Civil Engineering, Yantai University, China; Tel: +86 535 6902606; Fax: +86 535 690255; E-mail: cybshao@ytu.edu.cn reinforcement, and so on. In this paper, the method by increasing the thickness of chord near the weld toe is used to improve the static strength of tubular T-joint. This method of internal reinforcement for tubular $\mathrm{T}$-joint can not affect any appearance of the $\mathrm{T}$-joint and can maintain its aesthetic characteristics.

\section{FINITE ELEMENT ANALYSES FOR TUBULAR T-JOINT WITH CHORD REINFORCEMENT}

\section{Geometry of a Chord Reinforced Tubular Joint}

The geometry of a tubular T-joint reinforced with increasing chord thickness at the intersection is shown in Fig. (1). The thickness and the length of the reinforced chord are denoted by $T_{\mathrm{c}}$ and $L_{\mathrm{c}}$ respectively. Some normalized geometrical parameters generally used for describing a tubular T-joint are also listed in Fig. (1).

\section{Finite Element Modeling}

The finite element model is built by software ABAQUS which is a professional finite element analysis software to analyse complex and difficult nonlinear problems. For the steel material with obvious plastic flow feature, if the bilinear hardening model is adopted, the capacity of T-joint will be overestimated. Therefore, the ideal elastic-plastic model provided by software ABAQUS is used to simulate steel material. It meets Von Mises yield stress criterion. The material properties of the brace and the chord are defined as $206,000 \mathrm{~N} / \mathrm{mm}^{2}$ for modulus of elasticity $(E)$ and 0.3 for Poisson's ratio $(v)$. The yield stress of the steel material $\left(f_{\mathrm{y}}\right)$ is equal to $345 \mathrm{~N} / \mathrm{mm}^{2}$. 3-D structural solid elements (C3D8I) with 8 nodes are used to model the brace and the chord. From experience of previous work [6], the effects of the weld on static strength have been found to be insignificant. Therefore, the effects of weld in the intersection and the residual stress on the bearing capacity of the tubular $\mathrm{T}$-joints are ignored in the finite element analyses. The geometric 


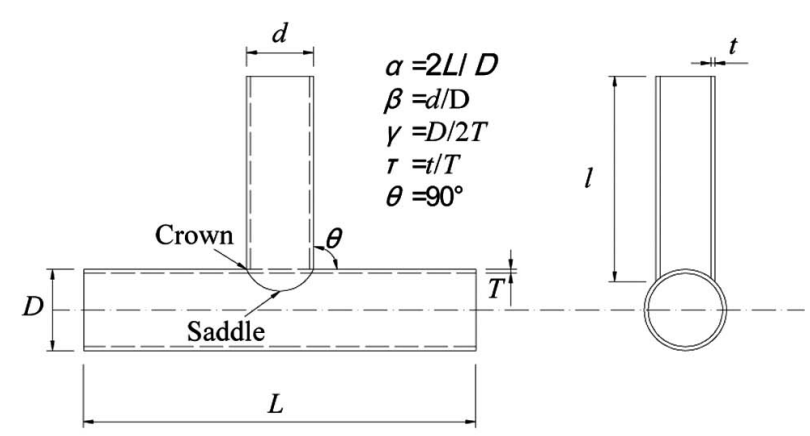

(a) un-reinforced model

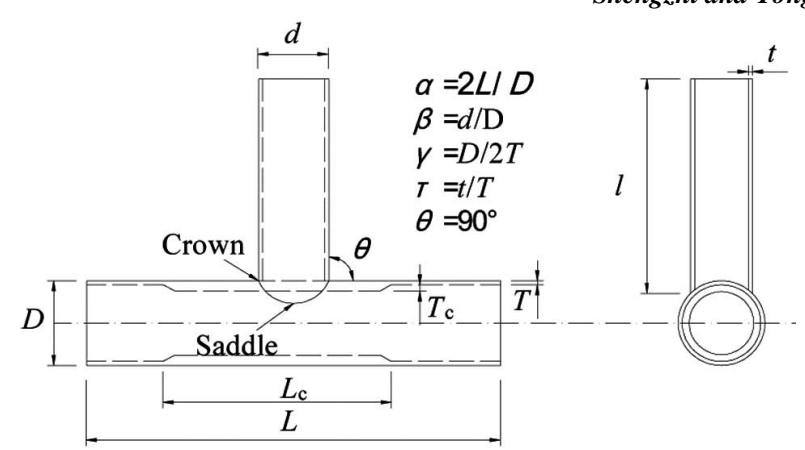

(b) reinforced model

Fig. (1). Geometrical model of tubular T-joint with chord un-reinforced and reinforced.
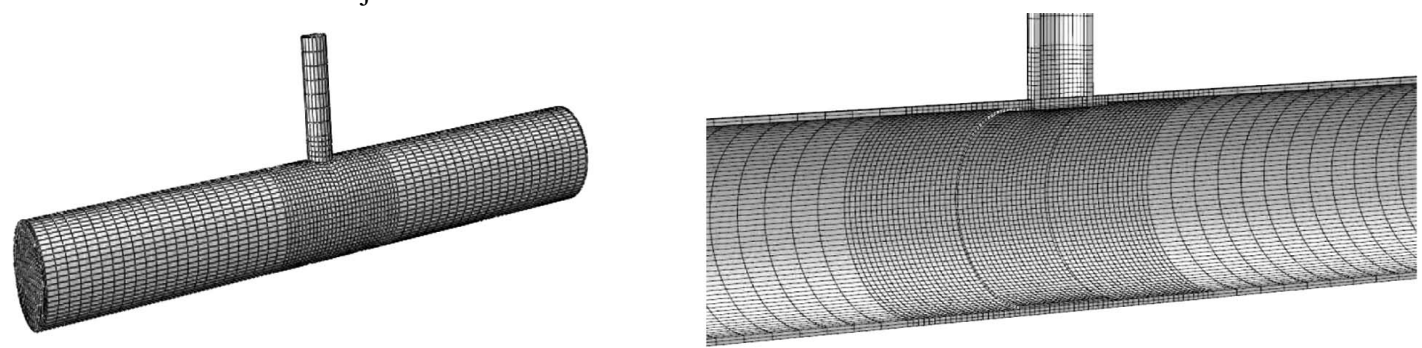

Fig. (2). Mesh of a tubular T-joint.

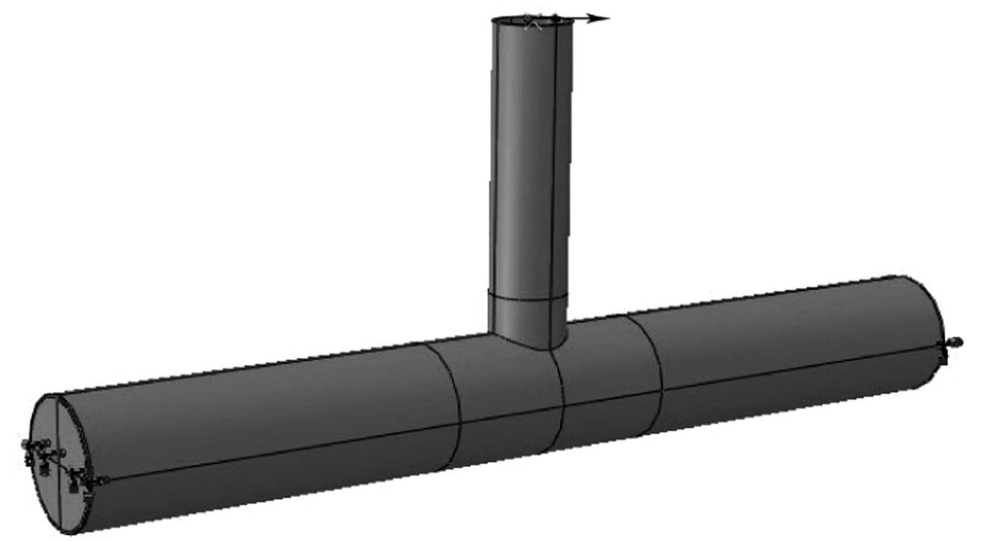

Fig. (3). Load and boundary condition of tubular T-joint.

nonlinear analysis is used throughout the analysis process. As the hot spot stress located at the weld, to obtain accurate numerical results and to increase computational efficiency, the mesh around the weld toe is refined while a relatively coarse mesh is used far away from the weld toe [7]. The approximate element size in the refine region is from $10 \mathrm{~mm}$ to $20 \mathrm{~mm}$, and that in the coarse region is from $45 \mathrm{~mm}$ to $60 \mathrm{~mm}$. The mesh of a typical T -joint is shown in Fig. (2). To avoid the local buckling of chord ends, two rigid plates are tied to the ends of chord (as shown in Fig. 3). Both ends for the chord are assumed as hinge joint by restraining the middle lines of the two end rigid plates (as shown in Fig. 3). The horizontal load is applied at a reference point which is located at the center of brace end. The reference point couples with the nodes at the brace end. The horizontal degree of freedom of the reference point is limited by using the displacement control method, and the degrees of freedom of the reference point in other directions are released. The horizontal displacement of the reference point is controlled to obtain the applied reaction force.

\section{NUMERICAL ANALYSIS}

\section{Comparison Between Reinforced Model and Un-Reinforced Model}

The computational results of the reinforced models are compared with those of the un-reinforced models to verify that the above presented reinforcement method is effective to improve static strength of a tubular $\mathrm{T}$-joint. The parameters of the reinforced and un-reinforced $\mathrm{T}$-joint models are shown in Table 1. Where $\beta$ is the brace-to-chord diameter ratio, $2 \gamma$ is the chord diameter-to-chord wall thickness ratio and $\tau$ is the chord wall thickness-to-brace wall thickness ratio. The specimens are divided into two groups. The un-reinforced and reinforced models of each group have the same geometric dimensions and material properties. The models of the two groups have different values of the parameters to compare with each other. The values of $\beta$ and $\gamma$ are taken from the range of validity which is presented by CIDECT guide [8] arbitrarily. The lengths of chord and brace adopt $7.5 \mathrm{D}$ and $5 d$ respectively. Two models of each group without and 
Table 1. Geometrical Parameters of Tubular T-Joint Models

\begin{tabular}{|c|c|c|c|c|c|c|c|c|}
\hline Model & Type & $\begin{array}{c}D \times T \times L \\
(m m \times m m \times m m)\end{array}$ & $\begin{array}{c}d \times t \times l \\
(m m \times m m \times m m)\end{array}$ & $\begin{array}{c}\beta \\
(d / D)\end{array}$ & $\begin{array}{c}2 \gamma \\
(D / T)\end{array}$ & $\begin{array}{c}\tau \\
(t / T)\end{array}$ & $L_{\mathrm{c}} / d$ & $T_{c} / T$ \\
\hline Model $\mathrm{A}_{1}$ & un-reinforced & $192 \times 6 \times 1440$ & $57.6 \times 6 \times 230.4$ & 0.3 & 16 & 1.0 & - & - \\
\hline Model $\mathrm{A}_{2}$ & reinforced & $192 \times 6 \times 1440$ & $57.6 \times 6 \times 230.4$ & 0.3 & 16 & 1.0 & 2.5 & 1.8 \\
\hline Model $\mathrm{B}_{1}$ & un-reinforced & $500 \times 10 \times 3750$ & $300 \times 10 \times 1200$ & 0.6 & 25 & 1.0 & - & - \\
\hline Model $\mathrm{B}_{2}$ & reinforced & $500 \times 10 \times 3750$ & $300 \times 10 \times 1200$ & 0.6 & 25 & 1.0 & 2.0 & 1.5 \\
\hline
\end{tabular}

with chord reinforcement are used to investigate the improvement of the static strength.

The moment-rotation curves of the four models are presented in Fig. (4). The horizontal displacement at the center of brace end plate is divided by the brace length to calculate the brace rotation $(\phi)$, and the value of moment $(M)$ is equal to the applied force times the brace length. The deformation limit proposed by Yura [9], as defined by $80 f_{\mathrm{y}} / E$, is adopted to determine the ultimate strength of joints in the case that there is no pronounced peak load in the moment-rotation curve. From Fig. (4), it can be seen that the static strength of tubular $\mathrm{T}$-joints are improved greatly by increasing the thickness of the chord. In Fig. (4a) and (4b), the brace end moments of the un-reinforced model $\mathrm{A}_{1}$ and the reinforced model $\mathrm{A}_{2}$ are $3.77 \mathrm{kN} . \mathrm{m}$ and $5.99 \mathrm{kN}$.m respectively, and the brace end moments of the un-reinforced model $\mathrm{B}_{1}$ and the reinforced model $\mathrm{B}_{2}$ are $139.67 \mathrm{kN}$.m and $229.5 \mathrm{kN}$.m respectively. Therefore, compared to the un-reinforced model, the static strength of the reinforced model $\mathrm{A}_{2}$ has been increased by $58.8 \%$, and for model $\mathrm{B}_{2}$ it has been increased by $64.3 \%$, which indicate that increasing the thickness of chord can improve the bearing capacity of tubular T-joint subjected to in-plane bending load effectively. From Fig. (4a) and (4b), it can be seen that the slope of the reinforced model's curve is bigger than that of un-reinforced model in the elastic stage. Therefore, the stiffness of the reinforced model in chord radial direction is also improved due to the reinforcement.

\section{Efficiency of Chord Reinforcement}

It is found from the above results that it is effective to improve the static strength of a tubular T-joint by increasing local chord thickness. To determine a reasonable size of the reinforcing length and thickness, the length and the thickness of the reinforced chord segment are used as two principal

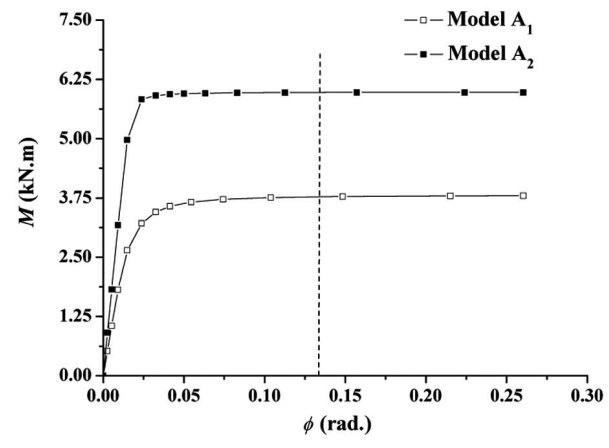

(a) Model A parameters in the efficiency of chord reinforcement study. The two parameters are normalized and denoted by $L_{\mathrm{c}} / d$ and $T_{\mathrm{c}} / T$ respectively. The lengths of the chord and the brace use consistent values of $7.5 \mathrm{D}$ and $4 d$ respectively. The values of $L_{\mathrm{c}} / d$ and $T_{\mathrm{c}} / T$ are listed in Table 2 . The two models in Table $\mathbf{1}$ are used for analysis in efficiency of chord reinforcement.

Table 2. Values of the Parameters

\begin{tabular}{|c|c|}
\hline $\boldsymbol{L}_{\boldsymbol{c}} / \boldsymbol{d}$ & $\boldsymbol{T}_{\boldsymbol{c}} \boldsymbol{T}$ \\
\hline \hline $1.5,2.0,2.5,3.0$ & $1.2,1.5,1.8,2.0$ \\
\hline
\end{tabular}

From Fig. (5a) and (5b) it can be found that it is more effective to increase the value of $T_{\mathrm{c}} / T$ to improve the static strength of a tubular $\mathrm{T}$-joint under in-plane bending load than to increase the value of $L_{\mathrm{c}} / d$. The brace end moment of tubular T-joint has almost no increase with the increase of $L_{\mathrm{c}} / d$. Therefore, the increase of $L_{\mathrm{c}} / d$ has a slight effect to improve the static strength of a tubular T-joint under inplane bending load. In Fig. (5a), for a tubular T-joint with small value of $\beta$, the static strength increases gradually with the increase of $T_{\mathrm{c}} / T$. When the value of the chord thickness ratio $T_{\mathrm{c}} / T$ is less than a certain value $\left(T_{\mathrm{c}} / T \leq 1.5\right)$, the static strength can be improved significantly by increasing the value of $T_{\mathrm{c}} / T$. However, when the value of the chord thickness ratio $T_{\mathrm{c}} / T$ is bigger than 1.5 , the failure mode has changed. Local buckling on the chord surface changes to yielding of brace at the intersection as shown in Figs. (6c) and $(\mathbf{6 d})$. The reason is that over-reinforcing the chord makes the reinforced chord segments very stiff. At this moment, it is not effective to improve the resistance of the Tjoints by increasing the value of $T_{\mathrm{c}} / T$ any further. For a tubular T-joint with large value of $\beta$, such critical value of $T_{\mathrm{c}} / T$ increases to be 1.8 .

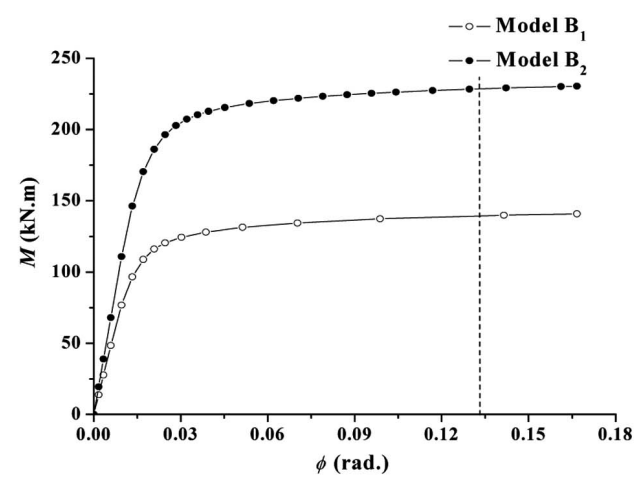

(b) Model B

Fig. (4). Moment-rotation curves of tubular T-joints loaded by in-Plane Bending. 


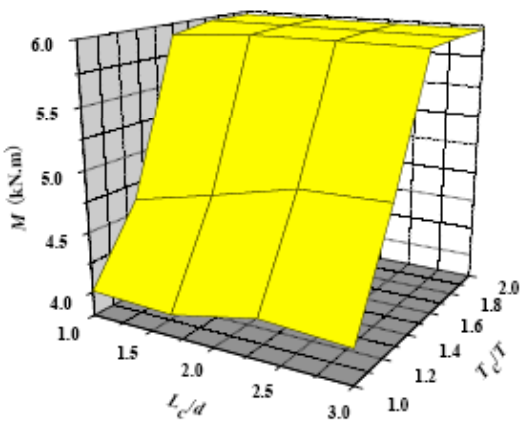

(a) $\beta=0.3$

Fig. (5). Efficiency of the reinforced length and thickness.

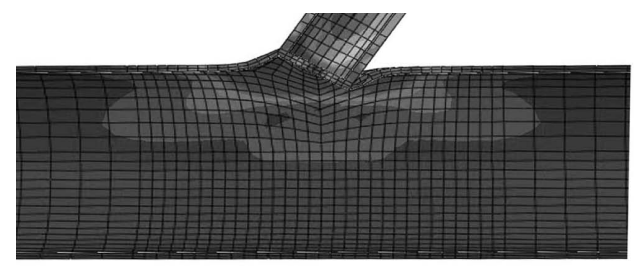

(a)

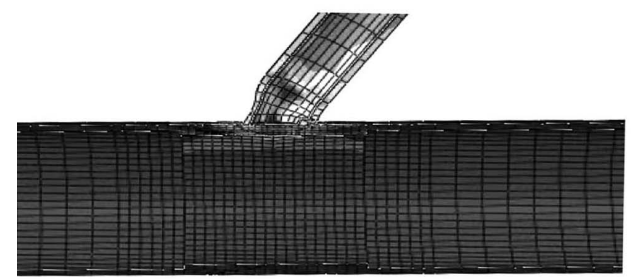

(c)

Fig. (6). The deformation of tubular T-joint.

\section{Failure Mode Analysis}

As shown in Fig. (6a), the un-reinforced tubular T-joint model fails in a form of local buckling on the chord surface around the brace and chord intersection. However, as shown in Fig. (6b), due to increasing the thickness of chord locally, the stiffness of chord in the radial direction has been improved. The deformation of the chord surface decreases gradually with the increase of $T_{\mathrm{c}} / T$. The brace at the intersection performs as yielding gradually. When the value of $T_{\mathrm{c}} / T$ exceeds a certain critical value, the deformation on the chord surface around the weld toe becomes quite small (as shown in Fig. (6c) and (6d)), and the brace near the intersection fails in a form of yielding completely since the present reinforced chord segment becomes much stronger.

\section{Parametric Analysis}

Based on the above analysis, it can be found that the influence of $T_{\mathrm{c}} / T$ for improving the static strength of a tubular $\mathrm{T}$-joint is greater than that of $L_{\mathrm{c}} / d$. To investigate the effect of some geometrical parameters and $T_{\mathrm{c}} / T$, parametric study is carried out. Geometrical parameters (i.e., the thickness of chord $T$, the brace/chord diameter ratio $\beta$, the chord diameter/thickness ratio $2 \gamma$ ) and $T_{\mathrm{c}} / T$ are used as parameters in the parametric study. The values of these parameters are listed in

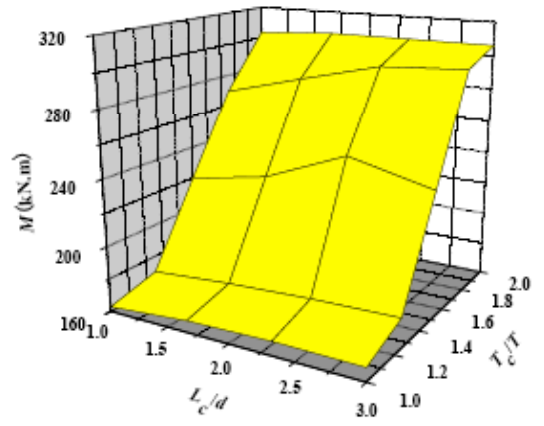

(b) $\beta=0.6$

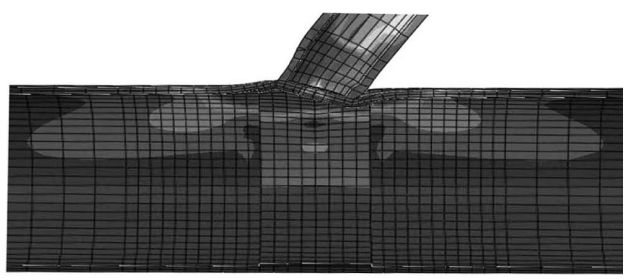

(b)

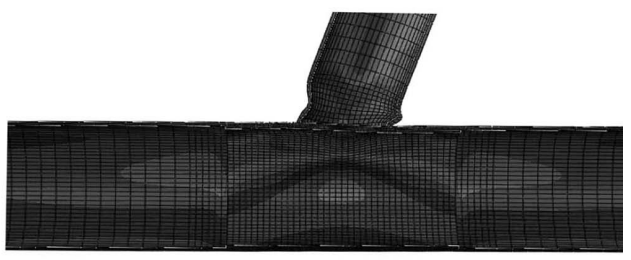

(d)

Table 3. Additionally, the reinforced chord length ratio $\left(L_{\mathrm{c}} / d\right)$ and the brace/chord thickness ratio $(t / T)$ are consistent, and the values are 2.5 and 1.0 respectively. The lengths of the chord and the brace still use consistent values of $7.5 \mathrm{D}$ and $4 d$ respectively.

Table 3. Values of the Parameters

\begin{tabular}{|c|c|c|c|}
\hline $\boldsymbol{\beta}$ & $\boldsymbol{\gamma}$ & $\boldsymbol{T}_{\mathrm{c}} \boldsymbol{T}$ & $\boldsymbol{T}(\boldsymbol{m m})$ \\
\hline \hline $0.3,0.45,0.6,0.8$ & $10,16,25,35$ & $1.2,1.5,1.8,2.0$ & $6,10,15$ \\
\hline
\end{tabular}

As shown in Fig. (7), when the value of the chord thickness ratio $\left(T_{c} / T\right)$ is less than a certain value $\left(T_{\mathrm{c}} / T \leq 1.5\right)$, the chord thickness ratio $\left(T_{c} / T\right)$ has a basically linear effect on the improvement of the static strength of a tubular $\mathrm{T}$-joint under in-plane bending load. If the value of $T_{c} / T$ exceeds a critical value, increasing the value of $T_{c} / T$ has no effect to improve the in-plane bending capacity of a tubular T-joint.

Fig. (8) and Fig. (9) show that it has small effect on improving the in-plane bending capacity of a tubular T-joint with small values of $\beta$ and $\gamma$ by increasing the value of $T_{c} / T$. The reason is that a smaller value of $\beta$ means that the brace is very thin when compared with that of the chord diameter and a small value of $\gamma$ means that the thickness of the chord is 


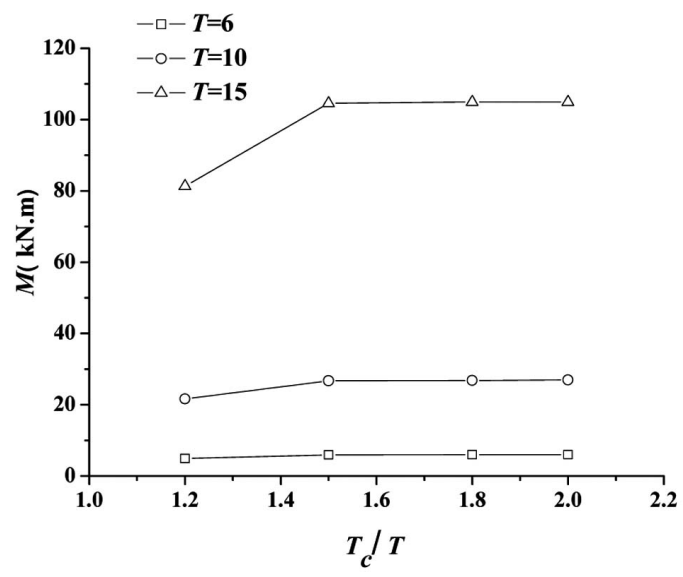

Fig. (7). Effect of chord thickness ratio $T_{c} / T$ on the in-plane bending capacity $(\beta=0.3, \gamma=16)$.

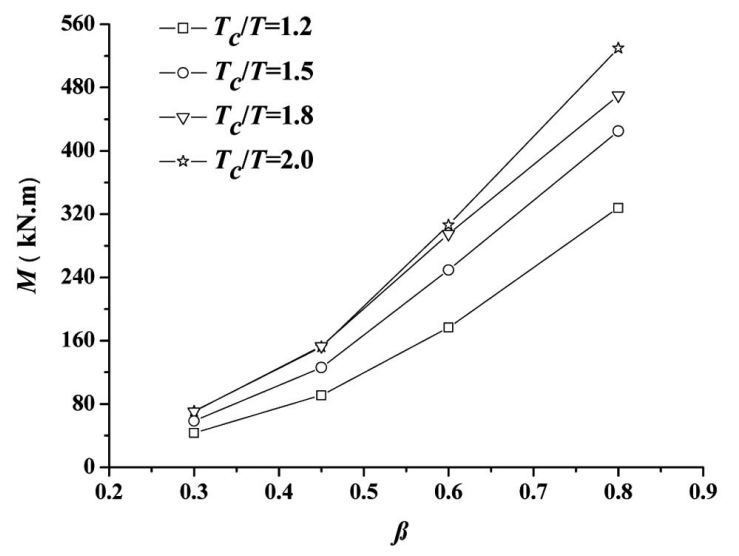

Fig. (8). Effect of $\beta$ on the in-plane bending capacity $(T=10, \gamma=25)$.

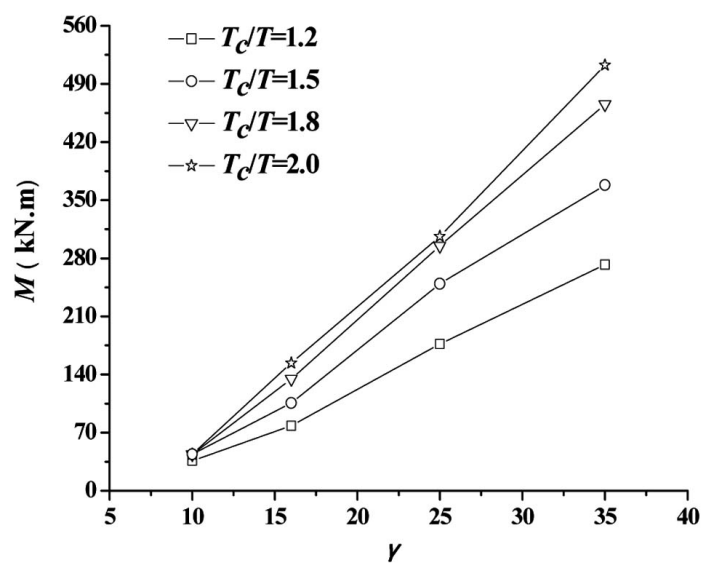

Fig. (9). Effect of $\gamma$ on the in-plane bending capacity $(T=10$, $\beta=0.6)$.

very large when compared with that of the radius, the stiffness in the radial direction of the chord is relatively larger, therefore, the failure modes both perform as local buckling in the brace, as shown in Fig. (6c) and (d). It also can be observed clearly from Fig. (8) and Fig. (9).

In Fig. (8), when the value of $\beta$ is less than 0.3 , the critical value of $T_{c} / T$ is 1.5 . When a tubular T-joint with large value of $\beta(0.3 \leq \beta \leq 0.5)$, the critical value of $T_{c} / T$ is 1.8 . When the value of $\beta$ is more than 0.5 , the critical value of $T_{c} / T$ increases gradually with the increase of $\beta$. The static strength of a tubular $\mathrm{T}$-joint under in-plane bending load increases remarkably with the increase of $\beta$. When the value of $\beta$ is relatively larger, the static strength of a tubular Tjoint can be improved significantly by increasing the value of $T_{c} / T$. However, increasing the value of $T_{c} / T$ is not effective to improve the static strength of a tubular T-joint with a small value of $\beta$.

As shown in Fig. (9), the effect of parameter $\gamma$ on the inplane bending capacity of a tubular T-joint can be seen as a linear relationship approximately. The increase of $\gamma$ can improve the in-plane bending capacity of tubular T-joint significantly. Similarly, parameter $\gamma$ has the same effect as parameter $\beta$ on the in-plane bending capacity of tubular $\mathrm{T}$ joint. When parameter $\gamma$ takes a small value, it has small influence on improving the static strength by increasing the value of $T_{c} / T$. However, the increasing efficiency is significant with a large value of $\gamma$.

\section{CONCLUSIONS}

Based on the finite element analysis and parametric study on tubular T-joints with chord reinforcement, if the geometry parameters of a tubular $\mathrm{T}$-joint are in a certain range $(0.3 \leq \beta \leq 0.8 ; 10 \leq \gamma \leq 35)$, the following conclusions can be drawn.

(1) Increasing chord thickness locally is effective to improve the static strength of a tubular T-joint under inplane bending load.

(2) It is more effective to increase the value of $T_{c} / T$ to improve the static strength of a tubular T-joint under in-plane bending load than to increase the value of $L_{\mathrm{c}} / d$.

(3) The value of $T_{c} / T$ should be in a certain range. Otherwise, it is not effective to improve the static strength of the tubular T-joints by increasing the value of $T_{c} / T$ any further. For a tubular T-joint with small value of $\beta$ $(\beta \leq 0.3)$, the critical value of $T_{c} / T$ is 1.5 . For a tubular T-joint with large value of $\beta(0.3 \leq \beta \leq 0.5)$, the critical value of $T_{c} / T$ is 1.8 . For a tubular T-joint with a larger value of $\beta(\beta \geq 0.5)$, the critical value of $T_{c} / T$ increases gradually with the increase of $\beta$.

(4) When the values of $\beta$ and $\gamma$ are relatively larger, increasing the value of $T_{c} / T$ can improve the static strength of a tubular T-joint greatly. However, the increasing efficiency is not obvious with small values of $\beta$ and $\gamma$.

\section{REFERENCES}

[1] Y. B. Shao, "Study on reinforcing methods for welded tubular joints structures", J. Yantai Univ (Natural Science and Engineering Edition), vol. 22, no. 4, pp. 312-320, 2009.

[2] M. M. K. Lee, and A. Llewelyn-Parry, "Offshore tubular T-joints reinforced with internal plain annular ring stiffeners", J. Struct. Eng. ASCE., vol. 130, no. 6, pp. 942-951, 2004.

[3] T. Li, Y. B. Shao, and J. C. Zhang, "Study on static strength of tubular joints reinforced with horizontal inner plate", Steel Construct, vol. 24, no. 123, pp. 25-29, 2009.

[4] Y. B. Shao, J. C. Zhang, Z. H. Qiu, and J. J. Shang, "Strength analysis of large-scale multiplanar tubular joints with inner-plate reinforcement". Int. J. Space Struct., vol. 24, no. 3, pp. 161-177, 2009.

[5] Y. S. Choo, J. X., Liang, G. J. van der Vegte and J. Y. R. Liew. "Static strength of doubler plate reinforced CHS X-joints loaded by 
in-plane bending". J. Construct. Steel Res., vol. 60, pp.1725-1744, 2004.

[6] M. M. K. Lee, and Llewelyn-Parry, "Strength of ring stiffened tubular T-joints in offshore structures-A numerical parametric study", J. Construct. Steel Res., vol. 51, pp. 239-264, 1999 a.

[7] G. J. Van der Vegte, Y. S. Choo, J. X. Liang, N. Zettlemoyer and J. Y. R. Liew, "Static strength of T-joints reinforced with doubler or collar plates. II: numerical simulations", J. Struct. Eng. ASCE., vol. 131, no. 1, pp. 129-138, 2005.

[8] X. L. Zhao, S. Herion, J. A. Packer, R. Puthli, G. Sedlacek, J. Wardenier, K. Weynand, A. van Wingerde, and N. Yeomans, "Design
Guide for Circular and Rectangular Hollow Section Joints under Fatigue Loading", CIDECT, TUV, 2000.

[9] J. A. Yura, N. Zettlemoyer, and I. F. Edwards, "Ultimate capacity equations for tubular joints", Proceedings of Offshore Technology Conference, Houston, USA, vol. I, OTC 3690, 1980.

[10] Y. S. Choo, J. X. Liang, G. J. van der Vegte and J. Y. R. Liew, "Static strength of collar plate reinforced CHS X-joints loaded by in-plane bending", J. Construct. Steel Res., vol. 60, pp.1745-1760, 2004.

(c) Shengzhi and Yongbo; Licensee Bentham Open.

This is an open access article licensed under the terms of the Creative Commons Attribution Non-Commercial License (http://creativecommons.org/licenses/by-nc/3.0/) which permits unrestricted, non-commercial use, distribution and reproduction in any medium, provided the work is properly cited. 